\title{
The EST Model for Predicting Progressive Damage and Failure of Open Hole Bending Specimens
}

\author{
Ashith P. K. Joseph* \\ Anthony M. Waas ${ }^{\dagger}$ \\ University of Michigan, Ann Arbor, MI, 48109 \\ University of Washington, Seattle, WA, 98195 \\ Evan J. Pineda ${ }^{\ddagger}$ \\ NASA Glenn Research Center, Cleveland, OH, $44113 \S$
}

\begin{abstract}
Progressive damage and failure in open hole composite laminate coupons subjected to flexural loading is modeled using Enhanced Schapery Theory (EST). Previous studies have demonstrated that EST can accurately predict the strength of open hole coupons under remote tensile and compressive loading states. This homogenized modeling approach uses single composite shell elements to represent the entire laminate in the thickness direction and significantly reduces computational cost. Therefore, when delaminations are not of concern or are active in the pre-peak regime, the version of EST presented here is a good engineering tool for predicting deformation response. Standard coupon level tests provides all the input data needed for the model and they are interpreted in conjunction with finite element (FE) based simulations. Open hole bending test results of three different IM7/8552 carbon fiber composite layups agree well with EST predictions. The model is able to accurately capture the curvature change and deformation localization in the specimen at and during the post catastrophic load drop event.
\end{abstract}

\section{Introduction}

Failure analysis of laminated fiber reinforced composite panels with open holes is a challenging problem because of the various failure modes involved and their mutual interactions. This complex problem presents the challenge of developing progressive failure analysis tools which can carry out the analysis in a cost effective and mesh-objective manner. Enhanced Schapery Theory (EST) $)^{1,2}$ achieves this task by accounting for the pre and post peak non-linearities using the Schapery theory ${ }^{3,4}$ and crack band ${ }^{5}$ models respectively. EST is a lamina level deformation, damage and failure prediction approach. Consequently, the inputs to EST that reflect the effects of damage and failure at scales below this scale (those that can be modeled using micromechanics, for example the kink band angle in fiber compression) must also be obtained in a manner that preserves the length scale of interest. Previous studies carried out by Davidson et al. ${ }^{6}$ and Joseph et al. ${ }^{2}$ presented a unified model for the open hole tension (OHT) and open hole compression (OHC) strength predictions using Enhanced Schapery Theory (EST). The EST model is extended in the present study to address the failure events when the open hole coupon is subjected to flexural loading. The complexity of the failure events due to the stress concentrations near the hole is escalated to the next level with the presence of a bending moment in the specimen that subjects some plies to tensile loading and others to compressive loading. Therefore, and unlike the in-plane tension or compression problem, a specimen subjected to bending has varying in-plane strains in the through-the-thickness direction and hence is a very good problem to validate any progressive failure model.

\footnotetext{
${ }^{*}$ Graduate Student Research Assistant, Department of Aerospace Engineering, AIAA Student Member

${ }^{\dagger}$ Boeing-Egtvedt Chair, William E Boeing Department of Aeronautics and Astronautics, 211E GUG, AIAA Fellow

${ }_{\ddagger}^{\ddagger}$ Aerospace Research Engineer, Mechanics and Life Prediction Branch, 21000 Brookpark Rd., MS 49-7, AIAA Member

$\S$ Copyright@ 2016, by Ashith Joseph, Anthony M. Waas and Evan Pineda. Published by the American Institute of Aeronautics and Astronautics, Inc., with permission.
} 
This paper compares EST predictions for three different IM7/8552 carbon fiber composite laminates under bending loading conditions with experiments. The results demonstrate ESTs capability for making excellent prediction while keeping computational costs to a minimum. Computational efficiency is achieved by using a single composite shell element for modeling all the layers in the thickness direction. The disadvantage of this approach is it's inability to capture delamination failure modes and therefore it is suitable for layup families where delamination events prior to the peak load point are negligible. This family, fortunately, is quite large.

\section{Finite Element Modeling}

Progressive failure of the open hole bending (OHB) specimens under 4-point bend loading conditions as shown in figure 1, is analyzed using EST. The model has a load span of $76.2 \mathrm{~mm}$ and a support span of $152.4 \mathrm{~mm}$. Abaqus general contact algorithm is used for modeling the contact between the plate and the load/support pins. Pins are modeled using Abaqus analytical rigid elements and the diameters of the support and load pins are $9.525 \mathrm{~mm}$ and $6.35 \mathrm{~mm}$ respectively. All the degrees of freedom of the support pins are fixed and displacements in the z-direction are applied on the loading pins. Finite element mesh (figure 2) used in the study satisfies the stress convergence requirements and the crack band requirements for element size. Geometric non-linearity is used in the model as the rotations are significant under flexural loading.

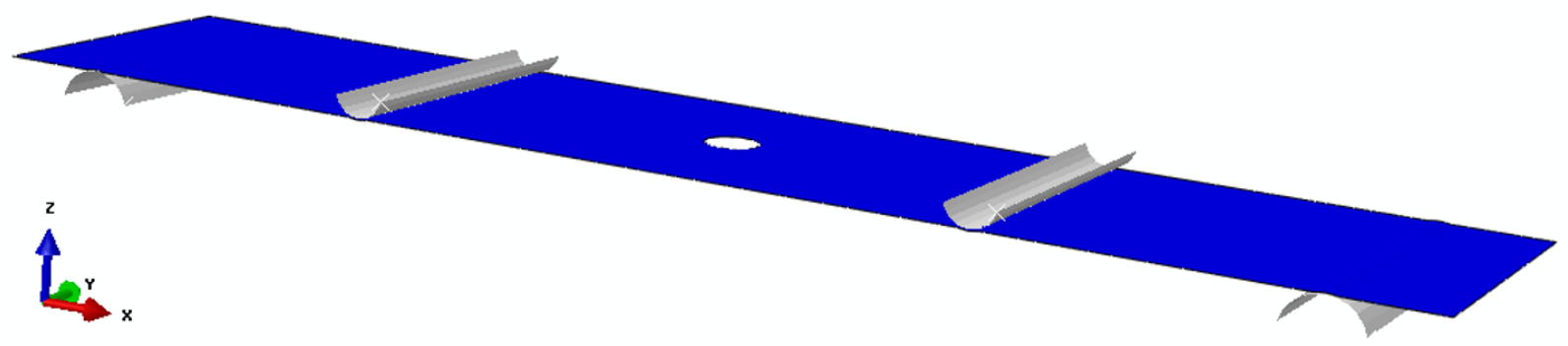

Figure 1. Open hole bending model

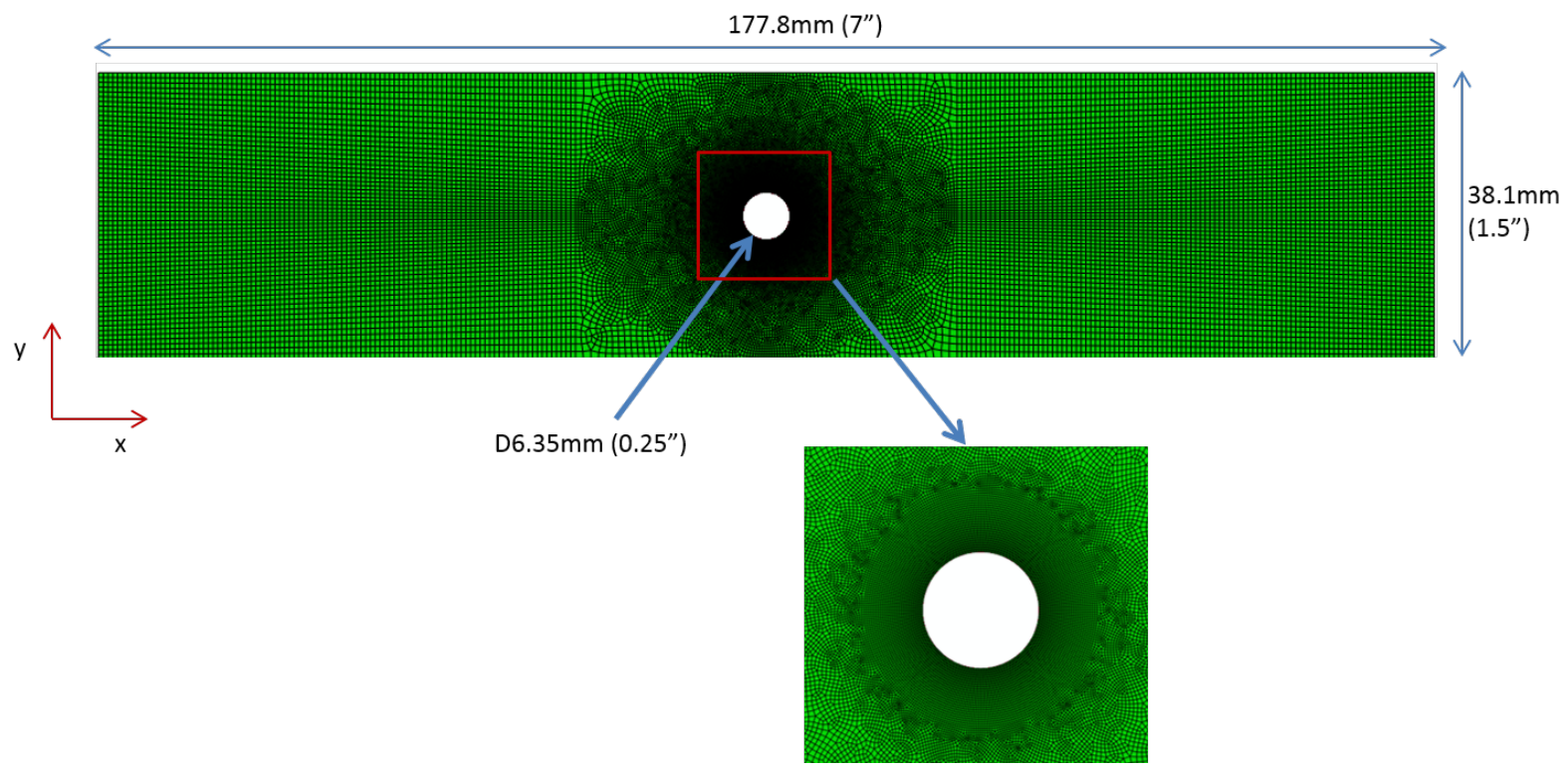

Figure 2. Finite element model mesh

EST is implemented as a user material subroutine (VUMAT) within the Abaqus/explicit solver (Abaqus is 
the name of a widely use commercial finite element software package) and the in-plane failure of the laminate is modeled using 4-node shell elements. Since EST cannot account for delamination mode of failure, the results obtained using EST are expected to give an upper bound for the strength of the laminate. Table 1 shows the three different layups used for the OHB analyses. The same mesh and modeling approach is used for all three layups and it was also found in the study that depending on the layup, mesh refinement requirements could be different. The mesh chosen here gives a converged gradient stress field near the hole for all three different layups.

\begin{tabular}{|c|c|}
\hline $\begin{array}{c}\text { Laminate } \\
\text { (\% 0 plies } / \% \mathbf{4 5} \text { plies } / \% \mathbf{9 0} \text { plies) }\end{array}$ & Lay-up \\
\hline $50 / 40 / 10$ & {$[0 / 45 / 0 / 90 / 0 /-45 / 0 / 45 / 0 /-45] \mathrm{s}$} \\
\hline $25 / 50 / 25$ & {$[45 / 0 /-45 / 90] 2 \mathrm{~s}$} \\
\hline $10 / 80 / 10$ & {$[45 /-45 / 0 / 45 /-45 / 90 / 45 /-45 / 45 /-45] \mathrm{s}$} \\
\hline
\end{tabular}

Table 1. List of laminates studied

\section{II.A. The EST Model and Input Parameters}
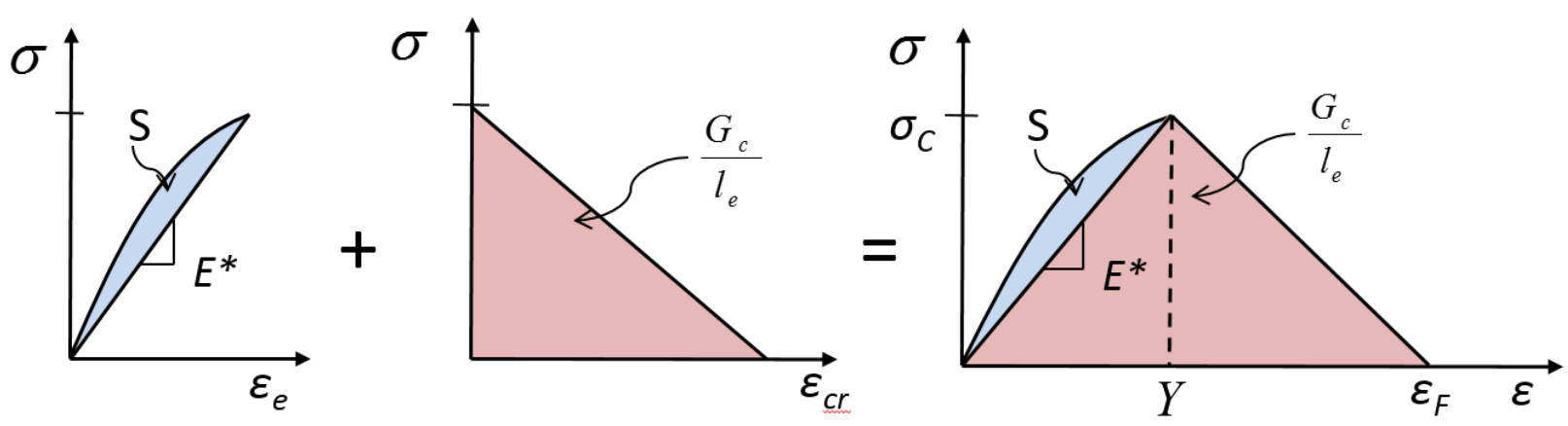

Figure 3. Stress-strain response of EST element

A typical stress-strain response of an EST element is shown in figure 3. The model assumes that the prepeak non-linearity is caused by the development of matrix micro-cracks, predominantly due to local states of shear (and also transverse strains). In EST micro-crack development is referred to as damage, while the coalescence of these microcracks which forms macroscopic crack is referred to as failure. In essence, if a suitable measure of stress and corresponding conjugate strain response shows a positive tangent stiffness (but one that changes), and if the instantaneous and decreasing tangent stiffness is positive, then damage is accruing at the microscale (which is how the body is dissipating energy), while the state at which this tangent stiffness for the first time becomes negative is identified as the onset of failure. Matrix micro-cracking affects only the transverse and shear stiffness properties and the axial stiffness value is unaffected by it. ${ }^{3,4}$ This assumption is valid as the axial stiffness is dominated by the fiber material properties. Schapery theory uses polynomial functions for representing the non-linear behavior in transverse and shear responses. Schapery microdamage functions used in this study are given in table 2 for IM7/8552. Shear microdamage functions are directly calculated from \pm 45 tension tests and the transverse microdamage response is obtained from the virtual testing of a representative unit cell (RUC) according to the procedure give in $\mathrm{Ng}$ et al. ${ }^{7}$ It is also assumed that transverse microdamge function is the same in both tension and compression, even though different responses are permitted within the theory. 


\begin{tabular}{|c|c|c|}
\hline \multicolumn{2}{|c|}{$\begin{array}{l}\text { Schapery Curves } \\
\left(\mathrm{Pa}^{-1 / 3}\right)\end{array}$} & Remark \\
\hline es0 & 1.0 & \multirow{6}{*}{$\begin{array}{l}\text { Transverse damage } \\
\text { coefficients in } \\
\text { tension/compression. } \\
\text { Calculated from virtual } \\
\text { transverse test of RUC using } \\
\pm 45^{\circ} \text { tension test results }\end{array}$} \\
\hline es1 & $-1.32 \mathrm{E}-3$ & \\
\hline es2 & $-5.7 E-5$ & \\
\hline es3 & $-3.29 E-7$ & \\
\hline es4 & $-6.94 \mathrm{E}-10$ & \\
\hline es5 & 0.0 & \\
\hline gs0 & 1.0 & \multirow{6}{*}{$\begin{array}{l}\text { Shear damage coefficients. } \\
\text { Calculated from } \pm 45^{\circ} \text { tension } \\
\text { test }\end{array}$} \\
\hline gs1 & $-7.36 \mathrm{E}-3$ & \\
\hline gs2 & $-2.7 \mathrm{E}-5$ & \\
\hline gs3 & $4.76 \mathrm{E}-7$ & \\
\hline gs4 & $1.28 \mathrm{E}-9$ & \\
\hline gs5 & $3.56 \mathrm{E}-11$ & \\
\hline
\end{tabular}

Table 2. Schapery microdamage functions

Microcracks that develop in the matrix coalesce to form macroscopic cracks, and at the onset of failure Schapery damage evolution is disabled in the model. In the absence of shear, transverse failure can occur without the development of micro-cracks or damage. Three main in-plane failure mechanisms are addressed in EST and these are matrix mode I cracking, matrix mode II cracking and axial fiber failure (mode I). While axial failure is independent of the matrix failure modes, matrix mode I and mode II failure are related to each other and their interaction is defined by a mixed-mode failure initiation and propagation laws. ${ }^{1,2}$ All three failure mechanisms are modeled using crack band theory. The fundamental principle behind the crack band theory is expressed by the equation below (equation 1 ).

$$
\varepsilon=\varepsilon_{e}+\varepsilon_{c r}
$$

Crack band theory is an effective, element level approach to model the onset and propagation of macroscopic cracks in a mesh objective manner. The theory is a two parameter failure model which requires the strength and fracture toughness parameters as input,. ${ }^{5}$ Strain-based initiation criteria define various failure mode initiations in EST. Upon the initiation of failure, the crack band model acts like entities in series with one representing the elastic part and the other representing the cracking mechanism. The total strain in the element is a sum of the elastic strain and the crack strain as shown in equation 1. This idea is effectively summarised in the figure 3. The area indicated by $S$ in the figure accounts for the energy dissipated due to microdamage evolution. $G_{c} / l_{e}$ term shows the energy dissipated in the case of failure, where $G_{c}$ is the fracture toughness of the material and $l_{e}$ is the element characteristic length perpendicular to the crack direction. 


\begin{tabular}{|c|c|c|}
\hline Property & $\begin{array}{l}\text { Value } \\
\text { (Units- SI) }\end{array}$ & Remark \\
\hline \multicolumn{3}{|c|}{ Lamina Properties } \\
\hline$E_{11}$ & $154.46 \mathrm{E}+09$ & {$\left[90^{\circ} / 0^{\circ}\right]_{s}$ Tension Test } \\
\hline$E_{22}$ & $7.20 \mathrm{E}+09$ & $90^{\circ}$ Tension Test \\
\hline $\mathrm{v}_{12}$ & 0.34 & $0^{\circ}$ Tension Test \\
\hline $\mathrm{G}_{12}$ & 4.87E+09 & $\pm 45^{\circ}$ Tension Test \\
\hline \multicolumn{3}{|c|}{ Failure Properties } \\
\hline$X_{T}$ & 0.0147 & $0^{\circ}$ Tension Test \\
\hline$X_{C}$ & 0.0131 & Predicted for $1.2^{\circ}$ fiber misalignment \\
\hline $\mathrm{Y}_{T}$ & 0.0080 & $90^{\circ}$ Tension Test \\
\hline $\mathrm{Y}_{C}$ & 0.0462 & $90^{\circ}$ Compression Test \\
\hline$Z$ & 0.0227 & $\pm 45^{\circ}$ Tension Test \\
\hline \multicolumn{3}{|c|}{ Fracture Toughness } \\
\hline$G_{I T}^{\mathrm{f}}$ & $\begin{array}{c}40.5 \mathrm{E}+3 \\
21.0 \mathrm{E}+3 \\
8.6 \mathrm{E}+3\end{array}$ & $\begin{array}{l}\text { For } 50 / 40 / 10,25 / 50 / 25 \text { and } 10 / 80 / 10 \\
\text { laminates respectively }\end{array}$ \\
\hline$G_{I C}^{\mathrm{f}}$ & $\begin{array}{c}10.1 \mathrm{E}+3 \\
5.3 \mathrm{E}+3 \\
2.2 \mathrm{E}+3\end{array}$ & $\begin{array}{l}\text { For } 50 / 40 / 10,25 / 50 / 25 \text { and } 10 / 80 / 10 \\
\text { laminates respectively }\end{array}$ \\
\hline$G_{I T}^{\mathrm{m}}$ & $0.384 \mathrm{E}+3$ & DCB Test \\
\hline$G_{I C}^{m}$ & $0.384 E+3$ & Assumed same as tension \\
\hline$G_{I I}^{\mathrm{m}}$ & $2.184 \mathrm{E}+3$ & ENF Test \\
\hline
\end{tabular}

Table 3. Material properties for EST

All the elastic and failure properties required for the EST model are shown in table 3. The axial and transverse stiffness properties are assumed to be the same in both tension and compression. But the failure properties are assumed to be different in tension and compression. One of the critical parameters which affects the peak load is the fiber direction fracture toughness. Since EST uses a single composite shell element, it is required to scale the fracture toughness with the layup according to the approach suggested by Camanho and Catalatonni. ${ }^{8}$ More discussions on the failure parameters can be found in Joseph et al. ${ }^{2}$ All the input parameter used in this open hole bending study are the same as the input parameters used in the previous open hole tension/compression study. ${ }^{2}$ The reader is advised to refer to Pineda and Waas ${ }^{1}$ and Joseph et al. ${ }^{2}$ for more details on the EST model. A discussion on the mesh-objectivity of the EST model can be found in Pineda and Waas. ${ }^{1}$

A limitation of the crack band model is the maximum element size which can be used for producing mesh objective results. This correspond to the element size for which the stress-strain response in figure 3 shows a vertical stress drop after the peak stress. Element sizes larger than this lead to physically incorrect snap-back behavior. The critical element length to prevent this behavior is given by,

$$
l_{e}<\min \left\{\frac{2 G_{I C}^{f} E_{110}}{X_{T}^{2}}, \frac{2 G_{I C}^{m} E_{22}^{*}}{Y_{T}^{2}}, \frac{2 G_{I I C}^{m} G_{12}^{*}}{Z^{2}}\right\}
$$




\section{Results and Discussion}

Failure events in the bending case are much more complex than in-plane loading cases such as open hole tension and open hole compression. When subjected to bending, the top layers of the specimen undergo compressive loading and the bottom layers undergo tensile loading. Figures 4, 6 and 8 show the load displacement plot form the EST simulations compared against the test results for the laminates 50/40/10, $25 / 50 / 25$ and 10/80/10 respectively. Load in the plots correspond to the total reaction force in the z-direction on the load pins and the displacement is the movement of the loading pin in the z-direction. For each layup EST simulations are compared against two test results. Table 4 shows the summary of the comparison.

\begin{tabular}{|c|c|c|c|c|}
\hline \multirow{2}{*}{ Laminate } & \multicolumn{2}{|c|}{ Peak Stress [kN] } & \multicolumn{2}{c|}{ Modulus [kN/mm] } \\
\cline { 2 - 5 } & $\begin{array}{c}\text { EST } \\
\text { Prediction }\end{array}$ & $\begin{array}{c}\text { Test } \\
\text { Data }\end{array}$ & $\begin{array}{c}\text { EST } \\
\text { Prediction }\end{array}$ & $\begin{array}{c}\text { Test } \\
\text { Data }\end{array}$ \\
\hline $50 / 40 / 10$ & 3.89 & 3.65 & 0.43 & 0.41 \\
\hline $25 / 50 / 25$ & 4.83 & 3.53 & 0.47 & 0.44 \\
\hline $10 / 80 / 10$ & 2.18 & 2.09 & 0.21 & 0.20 \\
\hline
\end{tabular}

Table 4. Open hole tension/compression results summary

For the 50/40/10 laminate, EST prediction agrees very well with the experiments as shown in figure 4. This layup has a large percentage of 0 layers and hence the strength is mainly driven by the fiber failure mechanisms. The approach of fiber direction fracture toughness scaling is also more appropriate in this layup due to the 0 layer dominance. Every +45 or -45 or 90 layer in this layup is sandwiched between 0 layers and this can significantly suppress the matrix failure mechanisms in them. This might not hold true if the $+45,-45$ or 90 layers were thicker as matrix failure events occur earlier in thick layers compared to thin layers. This example demonstrates that EST can accurately predict the results as long as the fiber failure properties are correct. Similar agreement between the experiments and simulations are seen in this layup for open hole tension/compression. ${ }^{2}$ Figure 5 shows the laminate degradation states corresponding to the three modes of failures at the two piece failure stage predicted by EST. It has to be kept in mind that the model cannot predict the crack paths accurately due to the accumulation of finite element stress calculation errors following element failure events. However the model is able to capture the two piece failure crack path fairly well in this case. While the fiber failure is over a narrow region, matrix failure is spread over a larger region as one would expect. 


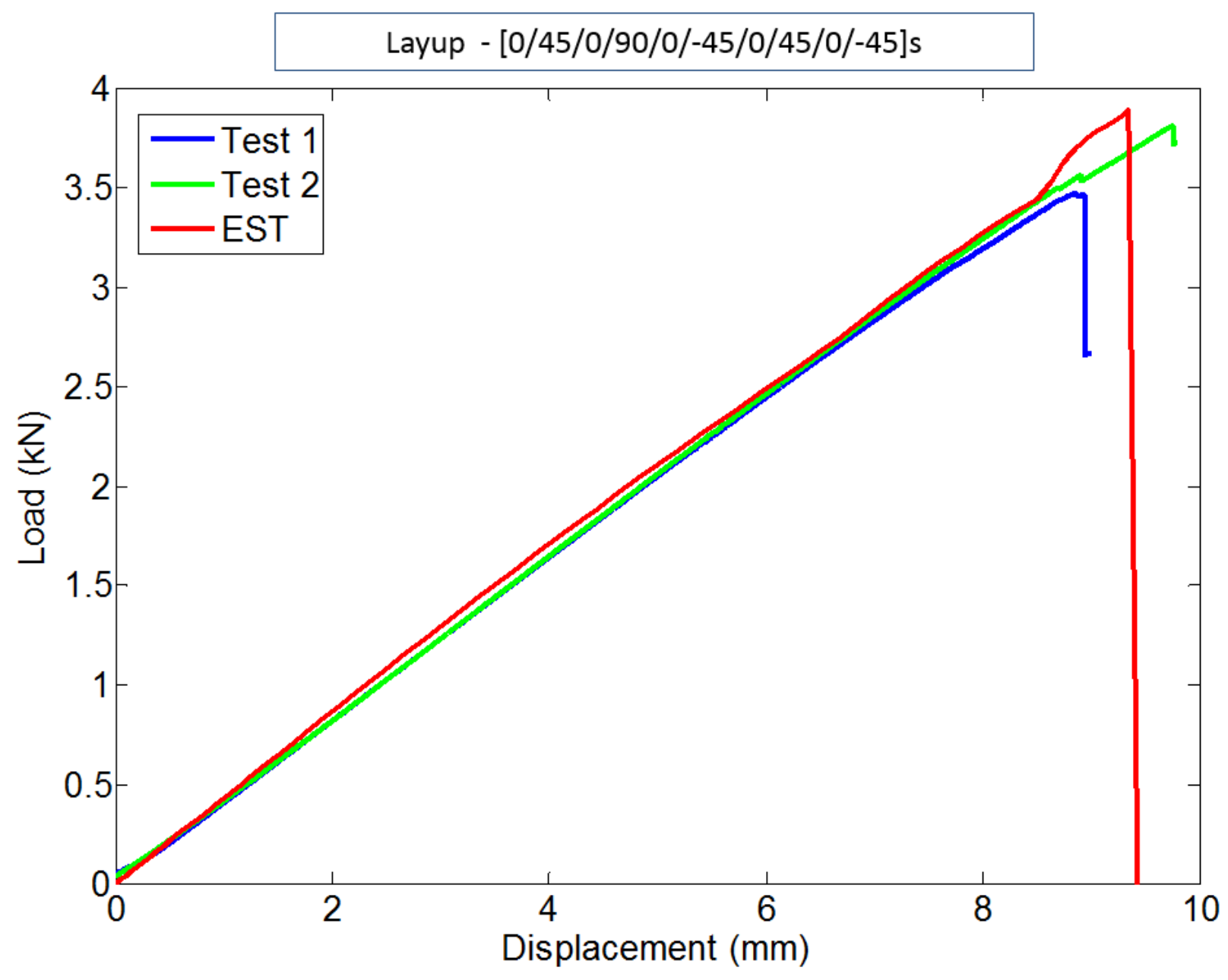

Figure 4. Load-displacement plot of 50/40/10 laminate coupon 


\section{Fiber Failure}
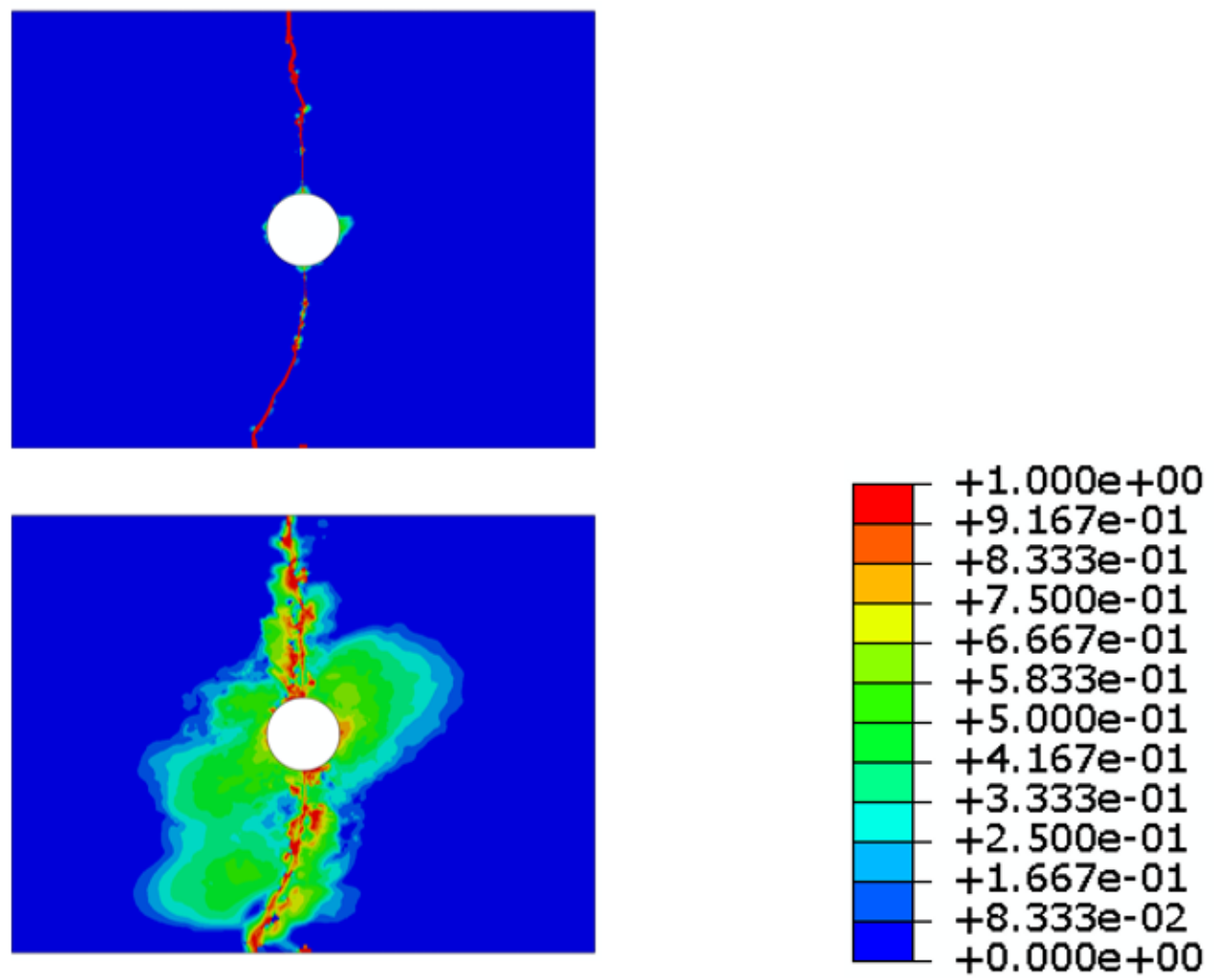

\section{Matrix Failure (mode II)}

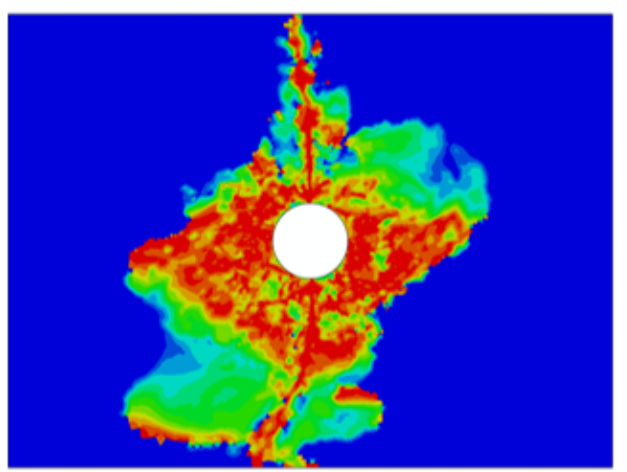

Figure 5. Failure of 50/40/10 laminate coupon under bending

EST prediction for the 25/50/25 laminate does not agree quite well with the experiments. There is significant variation between the test data itself. More number of tests are to be conducted for this layup to make a better comparison with simulation. However the larger non-linear region close to the peak load in the experimental curves indicate that delamination is a significant failure mechanism here. Larger peak load predicted by EST can be attributed to it's inability to account for delamination mode of failure. Degradation states shown in figure 7 indicates very large matrix failure region compared to other layups and suggests that future studies on this layup will have to include delamination interface elements in the model. A similar over-prediction behavior was also observed in the open hole tension/compression study of this layup. ${ }^{2}$ 


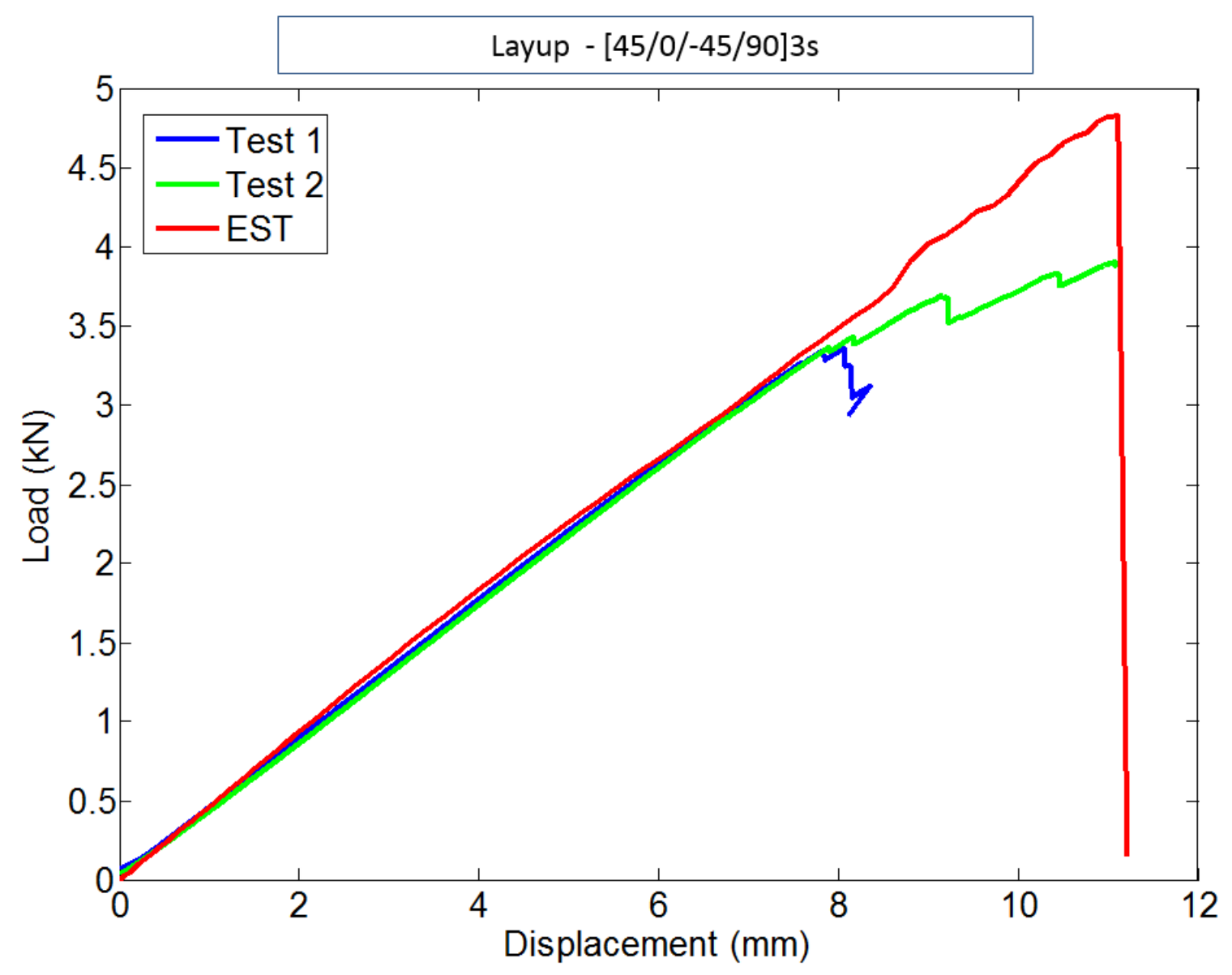

Figure 6. Load-displacement plot of 25/50/25 laminate coupon 

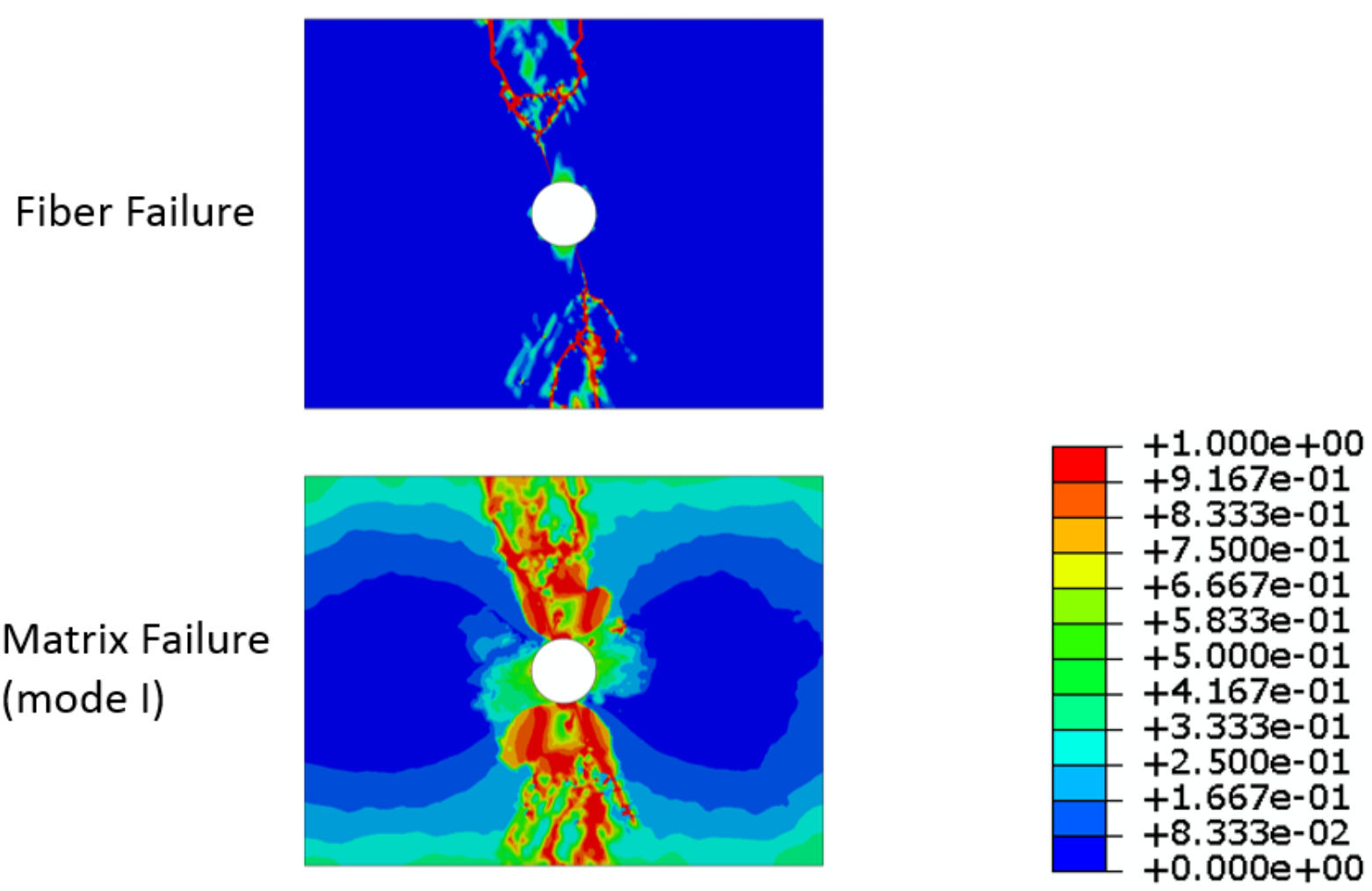

\section{Matrix Failure (mode I)}

\section{Matrix Failure (mode II)}

$+9.167 \mathrm{e}-01$ $+8.333 \mathrm{e}-01$ $+7.500 \mathrm{e}-01$ $+6.667 \mathrm{e}-01$ . $+4.167 \mathrm{e}-01$ $+3.333 \mathrm{e}-01$ $+2.500 \mathrm{e}-01$ $+1.667 \mathrm{e}-01$ $+0.000 e+00$

Figure 7. Failure of 25/50/25 laminate coupon under bending

Experiment-EST agreement is very good for the 10/80/10 laminate as shown in figure 8. Large number of $+45 /-45$ layers present in this laminate makes matrix failure events to be the main failure mechanism. Laminate fracture toughness of this laminate ( table 3) is much smaller compared to other laminates and hence matrix failure mechanisms has a big influence on the peak load value. Failure pattern shown in figure 9 indicate matrix failure patterns aligned along +45 nd -45 angles. Similar failure pattern aligned along the -45 angle was observed in the open hole tension/compression study of this layup. ${ }^{2}$ Larger percentage of the $+45 /-45$ layers in this layup makes the single shell model to pick failure paths along the dominant fiber orientations. 


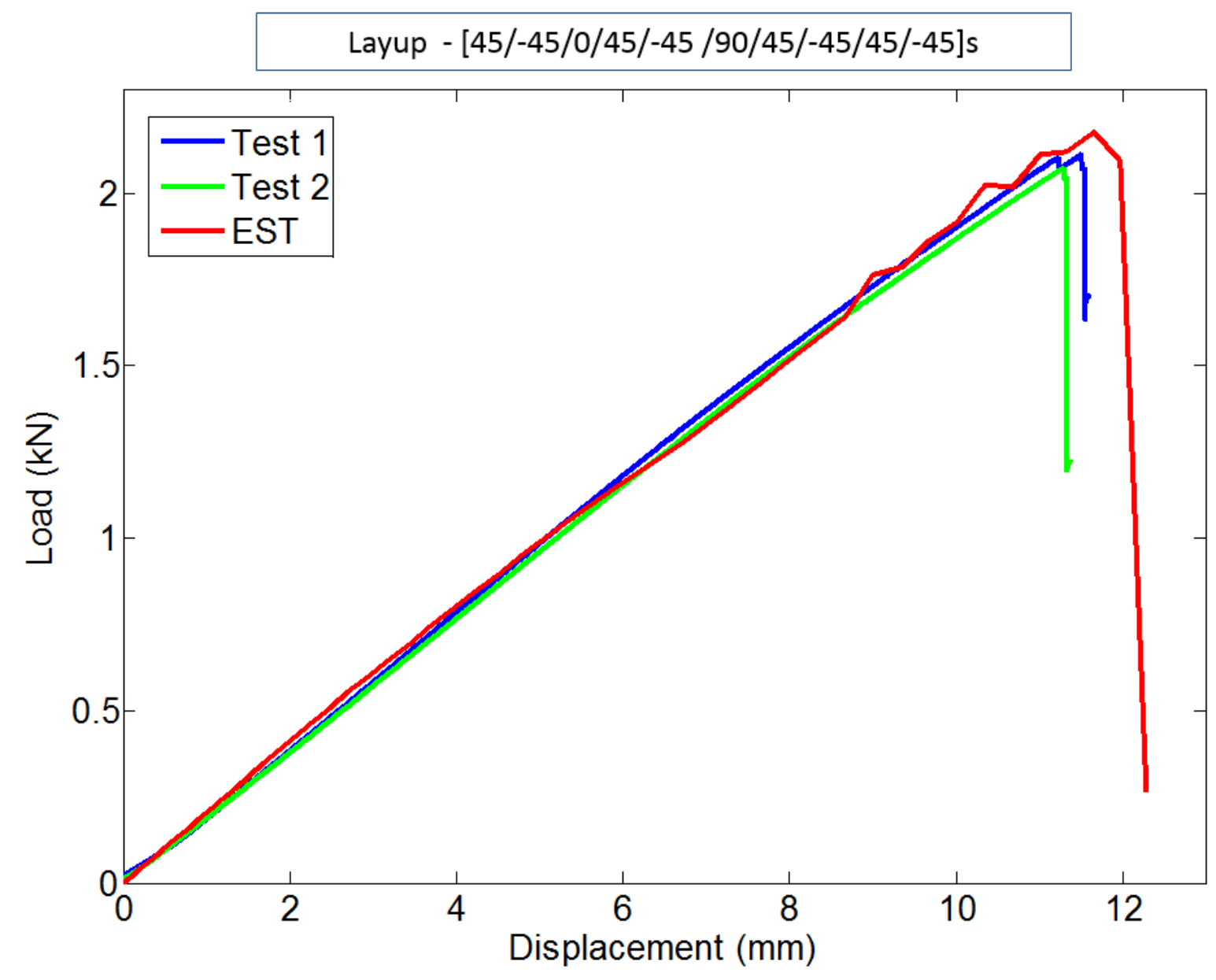

Figure 8. Load-displacement plot of 10/80/10 laminate coupon 


\section{Fiber Failure}

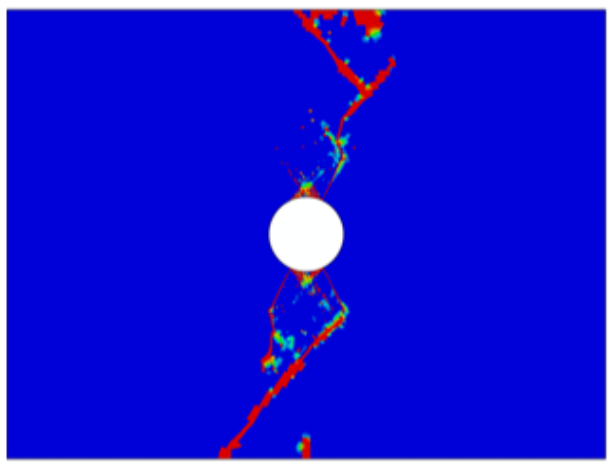

\section{Matrix Failure (mode I)}
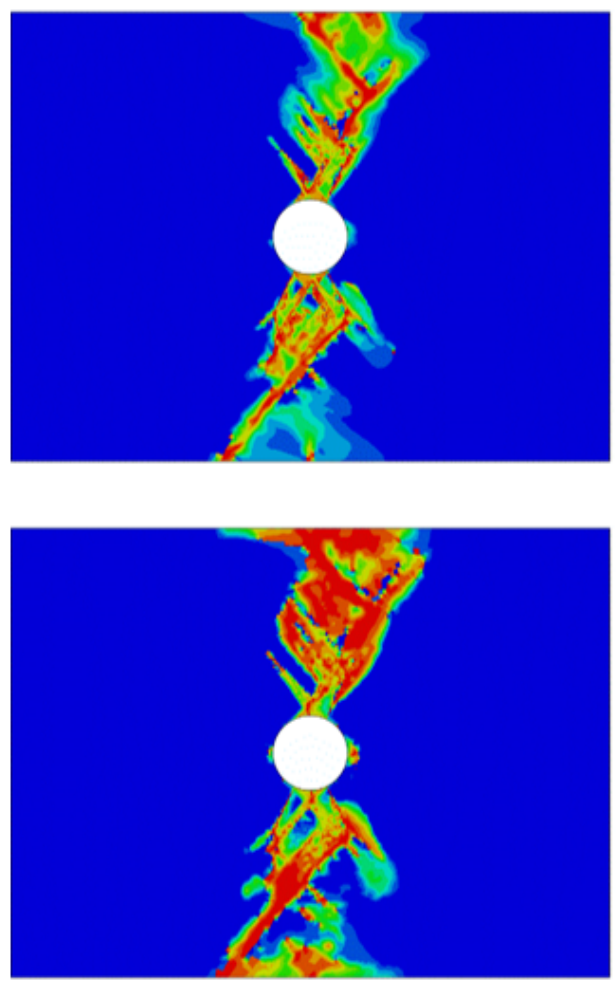

\section{Matrix Failure (mode II)}

$+1.000 \mathrm{e}+00$

$+9.167 \mathrm{e}-01$

$+8.333 \mathrm{e}-01$

$+7.500 \mathrm{e}-01$

$+6.667 \mathrm{e}-01$

$+5.833 \mathrm{e}-01$

$+5.000 \mathrm{e}-01$

$+4.167 \mathrm{e}-01$

$+3.333 \mathrm{e}-01$

$+2.500 \mathrm{e}-01$

$+1.667 \mathrm{e}-01$

$+8.333 \mathrm{e}-02$

$+0.000 \mathrm{e}+00$

Figure 9. Failure of 10/80/10 laminate coupon under bending

For all the layups studied, failure events are initiated by the tranvsverse/shear failure initiation in the 90/45 layer on the outer laminae under tension. The final load drop happens when the 0 layers fail in compression. Thus, compressive failure is a strength limiting mechanism. In the 10/80/10 laminate case, fiber failure is more controlled by the matrix failure in the adjacent layers. Since the failure strain and fracture toughness in the fiber direction are lower in compression than in tension, it is expected that the final failure occurs due to the compressive failure in the top layers. When this happens, instantaneous failure in the other layers due to compression/tension occurs and the specimen loses its load bearing capacity. A remarkable achievement of the present EST model is it's ability to capture the curvature change in the beam through the damage development, peak load attainment and post-peak response. Figure 10 shows the curvature of the beam just before the peak load and after the two-piece failure. 


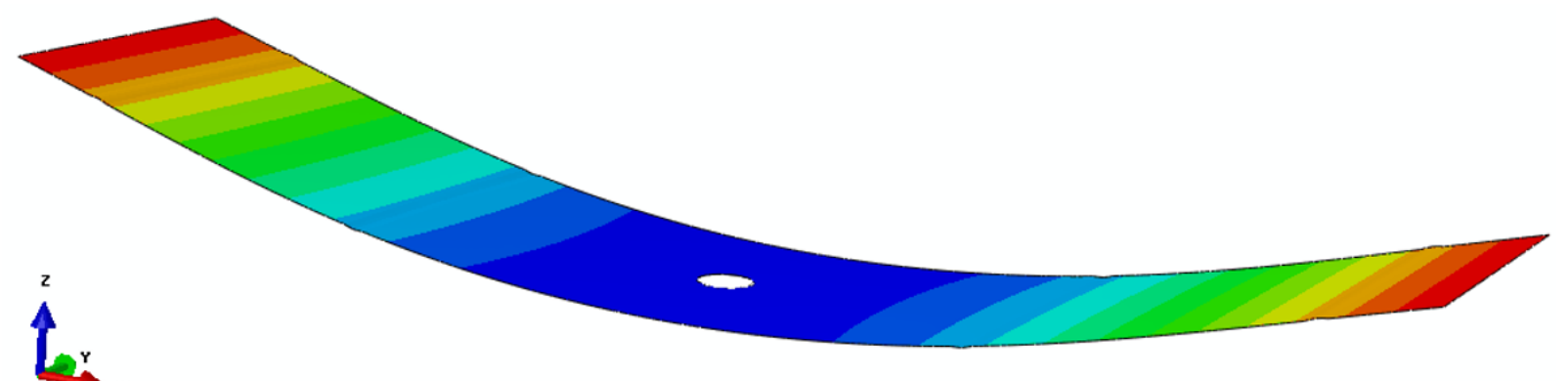

(a)

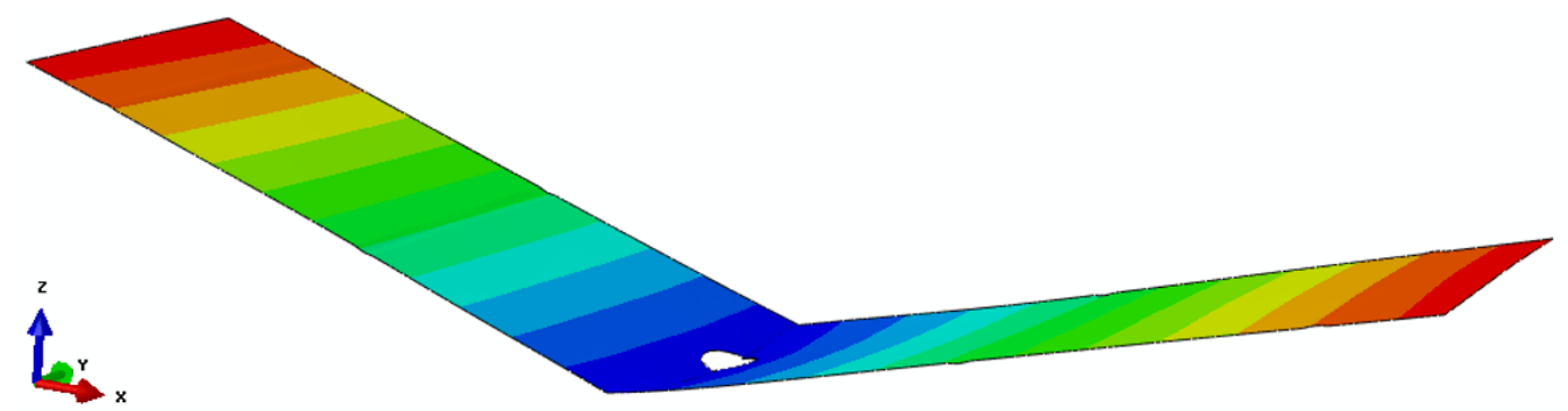

(b)

Figure 10. (a) Curvature of the beam before failure. (b) Curvature of the beam after failure

The laminate fracture toughness scaling used in this study is particularly suited for in-plane problems. More investigation is required to develop a better scaling condition for the bending case. Ideally, this can be achieved through a high-fidelity micromechanics study of a representative volume element that contains multiple laminae. For simplicity the effect of bending on laminate fracture toughness is ignored here. Even with all the limitations of a single shell model, it is quite remarkable that the EST model agrees very well with experimental data for the laminates studied here.

\section{Conclusion}

The validity of EST as a computationally efficient and accurate model for capturing the in-plane failure in a composite laminate with stress concentrations due to holes/notches has been established in previous studies. More complex loading conditions such as bending is addressed in the present study and the failure events due to that are predicted using EST. Overall, experimental results are found to agree very well with the EST predictions. Comparison shows that the modeling strategy can accurately predict the failure patterns and the change in curvature of the specimen after the catastrophic load drop. The model, as expected, is seen to over-predict the strength for layups and loading conditions when delamination is an important failure mechanism. More study on the laminate fracture toughness scaling is needed to address this issue. Another way of solving this issue is by including delamination interface elements, however this can increase the computational cost. In cases where lay-up rules permit to rule out delamination as an important failure mode (that is, those cases that show compressive peel stresses between layers), EST is a cost-effective predictive tool for virtual testing of composite structures.

\section{Acknowledgments}

The authors are grateful for the sponsorship from the Boeing company. Useful discussions with Salvatore Liguore, Brian Justusson and Joseph Schaefer are gratefully acknowledged. 


\section{References}

${ }^{1}$ Pineda, E. J. and Waas, A. M., "Numerical implementation of a multiple-ISV thermodynamically-based work potential theory for modeling progressive damage and failure in fiber-reinforced laminates," International Journal of Fracture, Vol. 182, No. 1, 2013, pp. 93-122.

${ }^{2}$ Joseph, A. P. K., Waas, A. M., Ji, W., Pineda, E. J., Liguore, S. L., and Wanthal, S. P., "Progressive Damage and Failure Prediction of Open Hole Tension and Open Hole Compression Specimens," AIAA/ASME/ASCE/AHS/ASC 56th Structures, Structural Dynamics, and Materials Conference, Kissimmee, FL, 2015.

${ }^{3}$ Schapery, R. A., "A theory of mechanical behavior of elastic media with growing damage and other changes in structure," Journal of Mechanics and Physics of Solids, Vol. 38, No. 2, 1990, pp. 215-153.

${ }^{4}$ Sicking, D. L., Mechanical characterization of nonlinear laminated composites with transverse crack growth, $\mathrm{Ph} . \mathrm{D}$. thesis, Texas A\&M University, College Station, Texas, 1992.

${ }^{5}$ Bazant, Z. P. and Oh, B. H., "Crack band theory for fracture of concrete," Materiaux et constructions, Vol. 16, No. 93, pp. $155-177$.

${ }^{6}$ Davidson, P., Pineda, E. J., Heinrich, C., and Waas, A. M., "A unified model for predicting the open hole tensile and compressive strengths of composite laminates for aerospace applications," AIAA/ASME/ASCE/AHS/ASC 54th Structures, Structural Dynamics, and Materials Conference, Boston, MA, 2013.

${ }^{7} \mathrm{Ng}$, W. H., Salvi, A. G., and Waas, A. M., "Characterization of the in-situ non-linear shear response of laminated fiberreinforced composites," Composites Science and Technology, Vol. 70, 2010, pp. 1126-1134.

${ }^{8}$ Camanho, P. P. and Catalanotti, G., "On the relation between the mode I fracture toughness of a compoiste laminate and that of a 0 py; Analytical model and Experimental Validation," Engineering Fracture Mechanics, Vol. 78, 2011, pp. 2535-2546. 